\title{
A Cross Sectional Assessment of Hospital Pharmacist's Perception towards Online Health Information in Quetta, Pakistan
}

\author{
Azfar Akram, Qaiser Iqbal, Sajjad Haider, Rabia Ishaq, Fahad Saleem* \\ Faculty of Pharmacy and Health Sciences, University of Baluchistan, Quetta, PAKISTAN.
}

Received: 16 November 2020;

Accepted: 28 December 2020

*Correspondence to:

Dr. Fahad Saleem,

Faculty of Pharmacy and Health Sciences,

University of Baluchistan, Quetta, PAKISTAN. Email:fahaduob@gmail.com

Copyright: (c) the author(s),publisher and licensee Indian Academy of Pharmacists. This is an open-access article distributed under the terms of the Creative Commons Attribution Non-Commercial License, which permits unrestricted non-commercial use, distribution, and reproduction in any medium, provided the original work is properly cited.

\begin{abstract}
Objectives: The current study aims to assess the perception towards use of online health-related information among hospital pharmacists practicing at public healthcare institutes of Quetta city, Pakistan. Methods: This was a questionnaire based cross sectional survey. Sampling frame of this study was all hospital pharmacists practicing at public hospitals of Quetta city, Pakistan. The data instrument consisted of three sections namely perception towards online health-related information, type of online health-related information used and barriers encountered while retrieving online health-related information. The data was coded and transferred to Statistical Package for Social Science $\vee 20.0$ and whereas both descriptive and inferential statistics were used for data elaboration. Results: Out of 116 hospital pharmacists, eight one responded with a response rate of $69.8 \%$. Majority $(86.4 \%)$ of the respondents agreed that the Internet provides useful and updated health-related information. Nearly $70 \%$ of the respondents were also of the opinion that it is their practice to visit an established website. The most sought out information was about drugs followed by general healthcare and disease-related information $(92.5 \%, 74.0 \%$ and $61.7 \%$ respectively). The main barrier $(40,49.3 \%)$ was profusion of health-related information that at times becomes a barrier in obtaining the right information retrieve to scan through from the Internet. Statistical significant differences $(p<0.05)$ were reported among educational status and certain items of the questionnaire whereby postgraduate pharmacists were more in agreement to the statements. Conclusion: It is evident that our respondents are connected to Internet for professional usage and integrate Internet as an adjunct support in their practice. However, certain barriers and limitations were also indentified. For an effective usage of internet based learning, the barriers need to be addressed and facilities should be provided to the hospital pharmacists so that they can utilize an important source of information during their professional practice.

Key words: Hospital pharmacists, Perception, Online Health Information.
\end{abstract}

\section{BACKGROUND}

The popularity of internet usage lead to its first conference in Geneva in 1994. ${ }^{[1]}$ Since then, the use of the Internet among general population saw an exponential increase. ${ }^{[2,3]}$ Today, digital technology has shaped as an important part of everyday activity, ${ }^{[4]}$ since people subscribe to broadband facilities reflecting their desire to take advantage of the Internet's potential. ${ }^{[3]}$ As of October 2020, World Internet statistics reported an estimate of 4.66 billion Internet users worldwide with most users are in Asia. ${ }^{[5]}$ However, North America had the largest penetration rate $(89 \%)$, while the internet penetration rate in the world reached to $49.2 \%{ }^{[5]}$

Shifting our concerns to internet use in healthcare, the internet has become a treasure trove of information. ${ }^{[6]}$ It has been also reported to be the largest online medical library in the world. ${ }^{[7]}$ In recent years, the internet has evolved as an important source of information on drugs and health. ${ }^{[8]}$ This has become possible because of taking advantage of easy access, anonymity and widely available information with just a few taps on mobile devices such as a smart phone, tablet or personal computers. ${ }^{\left[{ }^{[p]}\right.}$ Using the internet for online medical information is very popular among healthcare professionals. ${ }^{[10]} \mathrm{It}$ is a useful tool for distributing medical research guidelines and since 1996, medical professionals have gradually referred to resources online. ${ }^{[2]}$ Studies have shown an increase trend for professional purposes such as access to medical and health information. ${ }^{[4]}$ A study reported that $67 \%$ of pediatricians use web-based resources as the first "port of communication" to look for clinical inquiries. ${ }^{[10]}$ Nurses at medical facilities in New Zealand reported that almost all respondents $(92.8 \%)$ has access to health information online at home and at work. ${ }^{[11]}$ At the same time, a study showed that the most popular medical resource was the web portal, followed by the online database and electronic journals, all three of which rely on the internet. ${ }^{[8]}$

Given the emergence of the internet as a major health resource, ${ }^{[12]}$ several studies have been conducted to explore the point of view of healthcare professionals ranged widely in its methodology and terminology. At present, there has been little research implemented to study the use of online health information among Pakistani hospital pharmacists. Although pharmacists' practice in the hospital relies heavily on information technology, the published studies and literature are largely based outside of Pakistan. Considering the wide availability of health information over the internet and yet a paucity of empirical information, the current study describes the employment of internet technology in hospital pharmacy practice in Pakistan. It is important to gain insights and fill the current gap and knowledge of Pakistani hospital pharmacists with the integration of the internet in the practice of daily health care. Hospital pharmacists are strategically positioned to assist their patients in the selection and interpretation of health-related information from the internet..$^{[9]}$ Based on the observations, the current research is aimed to assess the perception and attitude towards use of internet 
health related information among hospital pharmacists who are currently practicing in Quetta city, Pakistan.

\section{Methods}

\section{Sampling method and study design}

Sampling frame of this study was all hospital pharmacists practicing at public hospitals of Quetta city, Pakistan. We identified a total of 116 hospital pharmacists being stationed at five hospitals (Director General Health, Government of Baluchistan; Official Communication) that fulfilled the inclusion criteria. Based on the objectives, we designed this study as a questionnaire-based, cross sectional survey.

\section{Study tool (development, reliability and validity)}

The research tool was constructed by the research team through extensive literature review. For this purpose, part of the statements of the tool were developed by the study frame work of Wan et al. ${ }^{[13]}$ as well as from published literatures. ${ }^{[14-17]}$

The tool was validated for face and content validity by experts at Faculty of Pharmacy and Health Sciences, University of Baluchistan, Quetta. Later, the tool was subjected to pilot study with ten (10) pharmacists. Little modification was need and the tool was rated as reliable with an alpha value of $0.8 .^{[18,19]}$ Data from the pilot study was not included in the main study.

The finalized instrument consisted of three sections namely perception towards online health-related information, type of online health-related information used and barriers encountered while retrieving online healthrelated information.

\section{Data collection, ethical matters and study period}

The first author was involved in data collection. The study' purpose as well as addressing confidentiality matters, where no disclosure of personal data was assured to the respondents. Participation for this research was voluntary and the respondents were informed about their rights to quit the study. Institutional Ethical Committee of Faculty of Pharmacy and Health Sciences, University of Baluchistan approved the study protocol and permission to conduct the study was also taken from Medical Superintendents of the respective hospitals. Verbal consent was also taken from the respondent. The data collection completed in three months $\left(1^{\text {st }}\right.$ Dec, 2019 till $29^{\text {th }}$ Feb 2020).

\section{Data coding and statistical analysis}

The data was coded and transferred to Statistical Package for Social Science v 20.0). The distribution of the data was assessed via Kolmogorov-Smirnov (KS) test and non-parametric tests were used accordingly. ${ }^{[20]}$ Descriptive analysis was performed to present the frequency and percentage demographic characteristics. Mann-Whitney test was used for dichotomous variables while Kruskal-Wallis test was used otherwise. ${ }^{[21]}$ Where significant associations were observed, mean rank comparison and Bonferroni correction was used for interpretation for Mann-Whitney and Kruskal-Wallis test respectively. ${ }^{[21]}$ For all analysis, $p<0.05$ was considered to be statistically significant.

\section{RESULTS}

Out of 116 hospital pharmacists, eight one responded with a response rate of $69.8 \%$. We excluded the ten pharmacists that were involved in pilot testing. Refusal of participation and leave on duty were major reasons of the decrease in response rate. The cohort was dominated by males $(71.6 \%)$; majority was aged between 28 to 37 years old and has experience of more than 10 years. A high proportion of the respondents had bachelor level of education. A preponderance of our respondents $(86.43 \%)$ stated that they always use online health sources for information retrieval as shown in Table 1.

\section{Perception towards Online Health-related Information}

Hospital pharmacists were asked about the perception towards online health-related information that is summarized in Table 2. Majority $(86.4 \%)$ of the respondents agreed that the Internet provides useful and updated health-related information. Nearly $70 \%$ of the respondents were also of the opinion that it is their practice to visit an established website. Inline to what is being reported, $61 \%$ of the pharmacists believed that the Internet has healthrelated information that they cannot find from other resources. However, $75 \%$ of the respondents stated that they need more practice in order to use the Internet to search health-related information effectively. Also, only $30 \%$ knew the criteria of determining the quality of the information that is being retrieved from the websites.

\section{Type of Online Health-related Information}

Hospital pharmacists were also asked about the kind of health-related information or professional activities carried out by them and the frequency of its use. It was evident that being a pharmacist the most sought out information was about drugs followed by general healthcare and diseaserelated information $(92.5 \%, 74.0 \%$ and $61.7 \%$ respectively). However, research journals, online CPDs, professional blogs and forums and retrieval of treatment guidelines were not commonly practiced by the respondents as shown in Table 3.

\section{Barriers towards Online Health-related Information}

The last section of the questionnaire offered an open assessment of barriers towards online health-related information. The main barrier (40, 49.3\%) was profusion of health-related information that at times becomes a barrier in obtaining the right information retrieve to scan through from the Internet. Subscription fee for online health-related resources was also reported by $45 \%$ of the respondents as a potential barrier towards online health-related information. Connectivity issues and non-availability of gadgets used for

\section{Table 1: Demographic characteristics of the study respondents.}

\begin{tabular}{|l|l|l|}
\hline Characteristics & Frequency & Percentage \\
\hline Age (years) & & \\
$28-37$ & 60 & 74.0 \\
$38-47$ & 21 & 26.0 \\
\hline Gender & & \\
Male & 58 & 71.6 \\
Female & 23 & 28.3 \\
\hline Educational level & & \\
B.Pharm & 15 & 18.5 \\
Pharm.D & 58 & 71.6 \\
M.Phil & 8 & 9.8 \\
\hline Working experience (years) & & \\
< 10 years & 20 & 24.6 \\
> 10 years & 61 & 75.4 \\
\hline Use of online health related information & & \\
Very often & 70 & 86.4 \\
To some extent & 11 & 13.6 \\
None & 0 & 0 \\
\hline
\end{tabular}




\begin{tabular}{|l|l|l|l|}
\hline \multirow{2}{*}{ Table 2: Respondents' perceptions towards online health-related information. } \\
\hline \multirow{2}{*}{ Questions } & \multicolumn{2}{|c|}{ Frequency (\%) } \\
\cline { 2 - 4 } & Agree & Neutral & Disagree \\
\hline $\begin{array}{l}\text { The Internet has health-related information that I cannot find in } \\
\text { other resources. }\end{array}$ & $50(61.7)$ & $20(24.6)$ & $11(13.5)$ \\
\hline $\begin{array}{l}\text { I am confident that I can determine the quality of online health- } \\
\text { related information. }\end{array}$ & $30(37.0)$ & $20(24.6)$ & $31(38.2)$ \\
\hline I am familiar with the criteria to evaluate a health-related website. & $15(18.5)$ & $10(11.7)$ & $56(69.1)$ \\
\hline The Internet provides useful health-related information. & $70(86.4)$ & $5(6.1)$ & $6(7.3)$ \\
\hline I can find up-to-date health- related information on the Internet. & $60(74.0)$ & $15(18.5)$ & $6(7.3)$ \\
\hline $\begin{array}{l}\text { It is easy to find appropriate online health-related information about } \\
\text { a particular topic. }\end{array}$ & $55(67.9)$ & $10(12.3)$ & $16(19.7)$ \\
\hline $\begin{array}{l}\text { I need more practice in order to use the Internet to search health- } \\
\text { related information effectively. }\end{array}$ & $60(74.0)$ & $1(1.3)$ & $20(24.6)$ \\
\hline I visit established trusted health-related websites only. & $57(70.3)$ & $20(24.6)$ & $4(4.9)$ \\
\hline I refer to blog, forum or social media for health-related information. & $20(24.6)$ & $15(18.5)$ & $46(56.7)$ \\
\hline
\end{tabular}

online search was also mentioned by $25 \%$ of the respondents. Lastly, some of the respondents also mentioned heavy work load and lack of time during their practice as a barrier in obtaining online health related information.

\section{Association between demographics and perception towards online health-related information}

Based on the data distribution, non-parametric tests were used to assess the association between demographics and perception towards online healthrelated information. Statistics significant difference $(p<0.05)$ was reported among educational level and the question "I am confident that I can determine the quality of online health-related information." Additionally, education was also reported to significant association between "I am familiar with the criteria to evaluate a bealth-related website" and "I refer to blog, forum or social media for healthrelated information" (0.003 and 0.007 respectively) as shown in Table 4 . The significant associations were later interpreted through Bonferroni correction. The interpretation revealed that hospital pharmacists with M.Phil degree were more in agreement to the statements when compared with pharmacists having Pharm.D or B.Pharm degree.

\section{Association between demographics and type of online health-related information}

As like it was reported in Table 4, statistical significant difference $(p<0.05)$ was again reported among educational level and the question "I read online journals/articles." Additionally, education was also reported to significant association between "I search for guidelines/protocol such as GINA, WHO, JNC etc." The significant associations were later interpreted through Bonferroni correction. The interpretation revealed that hospital pharmacists with M.Phil degree were more in agreement to the statements when compared with pharmacists having Pharm-D or B-Pharm degree (Table 5).

\section{DISCUSSION}

The current study was aimed to assess the use of online health-related information by the hospital pharmacists. Findings of the study do reveal that hospital pharmacists frequently use Internet to look for health-related information. Additionally, they also expressed their point of view, type of information searched and the barriers while retrieving online health information.

Majority of our respondents $(86 \%)$ used Internet for health-related information. Most of them also agreed that the Internet provides useful
Table 3: Type of Online Health-related Information retrieved by the respondents.

\begin{tabular}{|l|l|l|}
\hline \multirow{2}{*}{ Questions } & \multicolumn{2}{l|}{ Frequency (\%) } \\
\cline { 2 - 3 } & Yes & No \\
\hline $\begin{array}{l}\text { I search for disease-related information from the } \\
\text { Internet. }\end{array}$ & $50(61.7)$ & $31(38.3)$ \\
\hline $\begin{array}{l}\text { I search for general healthcare information from the } \\
\text { Internet. }\end{array}$ & $60(74.0)$ & $21(26.0)$ \\
\hline I search for drug-related information from the Internet. & $75(92.5)$ & $6(7.5)$ \\
\hline I read online journals/articles. & $15(18.5)$ & $66(81.5)$ \\
\hline I undertake online CPD/CME. & $10(12.3)$ & $71(87.4)$ \\
\hline $\begin{array}{l}\text { I contribute to online discussion forums on health topics. } \\
\text { I search for guidelines/protocol such as GINA, WHO, } \\
\text { JNC etc. }\end{array}$ & $12(14.8)$ & $69(85.2)$ \\
\hline
\end{tabular}

and updated health-related information and they could find appropriate information about particular topic easily. Our results are supported by studies of the same nature whereby literature reports Internet as a useful resource of health-related information in providing quick and up to date information. ${ }^{[15,17,22,23]}$ It was also revealed that majority of the respondents used trusted resources and high proportion of them claimed that they were confident in terms of determining the quality of online health-related information. Compared to the qualitative study conducted by See Wan et al. ${ }^{[13]}$ our findings are against to what was reported by the authors. Few of our respondents knew the criteria of evaluating health-related websites and a possible difference is the practice of pharmacy in the two different healthcare settings. Where Malaysia has a well-developed pharmacy system, pharmacists in Pakistan are still involved in the traditional practice i.e. dispensing of medication and that might have caused the difference of opinion among the two groups. Also, majority of our respondents also agreed that they need more practice in searching online health-related information. Lack of computerbased literacy can be one factor as the pharmacists are only introduced to "Computers and Its Applications in Pharmacy" as a minor subject during their undergraduate studies in Pakistan. ${ }^{[24]}$ No further trainings or formal internships regarding the use of computers in pharmacy are available for the undergraduates. Therefore, before going to the practice environment, investigation should assess the hospital pharmacist's knowledge in terms of evaluating and verifying the credibility of web-based health-related resources, such as checking the information provider and last update of the websites and whether the information was accredited by URAC or HON code standards. ${ }^{[25]}$ 


\begin{tabular}{|c|c|c|c|c|c|}
\hline \multirow[b]{2}{*}{ Items in questionnaire } & \multicolumn{5}{|c|}{$P$-Value } \\
\hline & Age* $^{*}$ & Gender* & $\begin{array}{l}\text { Educational } \\
\text { level }{ }^{* *}\end{array}$ & $\begin{array}{c}\text { Working } \\
\text { Experience* }\end{array}$ & $\begin{array}{l}\text { Use of online health related } \\
\text { information** }\end{array}$ \\
\hline $\begin{array}{l}\text { The Internet has health-related information that I cannot find in } \\
\text { other resources. }\end{array}$ & 0.762 & 0.753 & 0.325 & 0.428 & 0.089 \\
\hline $\begin{array}{l}\text { I am confident that I can determine the quality of online health- } \\
\text { related information. }\end{array}$ & 0.658 & 0.306 & 0.045 & 0.107 & 0.204 \\
\hline I am familiar with the criteria to evaluate a health-related website. & 0.051 & 0.715 & 0.003 & 0.064 & 0.991 \\
\hline The Internet provides useful health-related information. & 0.702 & 0.749 & 0.895 & 0.137 & 0.782 \\
\hline I can find up-to-date health- related information on the Internet. & 0.743 & 0.288 & 0.897 & 0.573 & 0.464 \\
\hline $\begin{array}{l}\text { It is easy to find appropriate online health-related information } \\
\text { about a particular topic. }\end{array}$ & 0.763 & 0.622 & 0.931 & 0.314 & 0.096 \\
\hline $\begin{array}{l}\text { I need more practice in order to use the Internet to search health- } \\
\text { related information effectively. }\end{array}$ & 0.555 & 0.672 & 0.206 & 0.728 & 0.054 \\
\hline I visit established trusted health-related websites only. & 0.818 & 0.661 & 0.080 & 0.519 & 0.541 \\
\hline $\begin{array}{l}\text { I refer to blog, forum or social media for health-related } \\
\text { information. }\end{array}$ & 0.524 & 0.201 & 0.007 & 0.549 & 0.976 \\
\hline
\end{tabular}

*Mann Whitney test, ${ }^{* *}$ Kruskal Wallis Test

Table 5: Association between demographics and type of online health-related information.

\begin{tabular}{|c|c|c|c|c|c|}
\hline \multirow[b]{2}{*}{ Items in questionnaire } & \multicolumn{5}{|c|}{$P$-Value } \\
\hline & $\mathrm{Age}^{*}$ & Gender* & $\begin{array}{l}\text { Educational } \\
\text { level }^{* *}\end{array}$ & $\begin{array}{l}\text { Working } \\
\text { Experience* }\end{array}$ & $\begin{array}{l}\text { Use of online } \\
\text { health related } \\
\text { information** }\end{array}$ \\
\hline I search for disease-related information from the Internet. & 0.820 & 0.199 & 0.496 & 0.434 & 0.727 \\
\hline I search for general healthcare information from the Internet. & 0.374 & 0.267 & 0.032 & 0.333 & 0.468 \\
\hline I search for drug-related information from the Internet. & 0.753 & 0.037 & 0.128 & 0.191 & 0.844 \\
\hline I read online journals/articles. & 0.768 & 0.583 & 0.002 & 0.792 & 0.803 \\
\hline I undertake online CPD/CME. & 0.277 & 0.023 & 0.054 & 0.495 & 0.682 \\
\hline I contribute to online discussion forums on health topics. & 0.262 & 0.079 & 0.128 & 0.572 & 0.971 \\
\hline I search for guidelines/protocol such as GINA, WHO, JNC etc. & 0.879 & 0.047 & 0.045 & 0.384 & 0.263 \\
\hline
\end{tabular}

* Mann Whitney test, ${ }^{*}$ Kruskal Wallis Test

A notable finding was the use of social media for health information, where more than $50 \%$ of our respondents did not prefer to use blogs and social media. Parallel to this finding, Muhlen and Machado in their review clearly reported the concerns with the use of social media. The authors stated that social media provides unprofessional content and has the potential of breaching patient privacy. ${ }^{[26]}$ On the other hand, the use of social media for health-related information is commonly reported. Social platforms such as Facebook, Twitter and smart phone software applications are commonly reported in retrieving health-related information. ${ }^{[27]}$ Although the question of authenticity is always highlighted, certain certified digital technologies should be accepted by the hospital pharmacists into their professional practice that can help in providing patient education through modern communication channels. Therefore, we urge to redefine the term 'social media' and explore it further in upcoming studies.

The most searched topics were drug-related information followed by general health care and disease-related information. It is obvious that hospital pharmacists being the curator of drugs are more likely to deal with drug-orientated information instead of broader range of health-related information. ${ }^{[17]}$ Moreover, few respondents agreed that they search for online journals / which is against to a study conducted in Northern Ireland that reported online journals as the most visited websites for online health- related information. ${ }^{[17]}$ The same was with undertaking CMEs and CPDs for professional growth and enhancement of personal expertise. CMEs and CPDs are crucial for professional growth and the reasons of non-participating shall be explored in future studies. Our suggestions are supported by Farsi and colleagues whereby the authors also supported the importance of CPDs and CMEs. ${ }^{[28]}$

We also asked the respondents about the barriers that might hinder them from retrieving health-related information from Internet. Overwhelming of online health was reported and that was also evident from literature. ${ }^{[29,30]}$ Naturally, with the wealth of information available at the worldwide web and new information being continuously being added to the pool, it is obvious that retrieving the required information becomes a difficult task. One possible solution to this issue develops the ability to critically evaluate the information among users during the graduation timings. In accordance, subscription fees and poor infra-structure was also reported as a potential barrier towards online health-related information. Pakistan being a developing country faces issues related to poor infrastructure of internet facilities and availability of resources. Healthcare is already faced with huge burden in terms of human recourses, medicines and supplies and providing internet facilities and internetrelated infrastructure seems difficult at this moment. However, we urge 
the policymakers and administrators to look into this matter and to provide facilities so that healthcare professionals can perform their duties effectively and efficiently.

Lastly, the association analysis reported significant findings among educational level and certain items of the questionnaire where pharmacists with M.Phil education agreed more to the statements. Hospital pharmacists with M.Phil education are exposed to advanced topics like online retrieving of information and quality assessment of websites. In addition, they are also in practice of reading online articles and multiple guidelines. This perhaps is due to the training of the pharmacists during their post-graduation that requires extensive literature review and thesis write-up. Furthermore, an advanced level of education is always a positive factor in retrieving information that is not usually practiced by the other pharmacists. Continuous education in healthcare is a key that fosters new ideas and innovations as supported literature. ${ }^{[31]}$

\section{CONCLUSION}

The study highlighted the Internet usage for online health information among hospital pharmacists in Quetta city, Pakistan. It is evident that hospital pharmacist are connected to Internet for professional usage and integrating Internet as an adjunct support in their practice. However, certain barriers and limitations were also indentified. For an effective usage of internet based learning, the barriers need to be addressed and facilities should be provided to the hospital pharmacists so that they can utilize an important source of information during their professional practice.

\section{Limitations}

The study was focused on hospital pharmacists of a single city and results are not generalized. A more thorough study with a diversified and larger sample size is hereby recommended.

\section{ACKNOWLEDGEMENT}

We acknowledge the pharmacists for their time and participation in the current study.

\section{CONFLICT OF INTEREST}

The authors declare that there is no conflict of interest.

\section{REFERENCES}

1. Masters K. For what purpose and reasons do doctors use the Internet: $A$ systematic review. Int J Med Inform. 2008;77(1):4-16.

2. Younger $P$. Internet-based information-seeking behaviour amongst doctors and nurses: a short review of the literature. Health Info Libr J. 2010;27(1):2-10.

3. Schiavo R. The rise of e-health: current trends and topics on online health communications. J Medical Mark. 2008;8(1):9-18.

4. Higgins O, Sixsmith J, Barry MM, Domegan C. A literature review on health information seeking behaviour on the web: A health consumer and health professional perspective. Stockholm. 2011.

5. Statistica. Global digital population as of October 2020. 2020. [2 December 2020]. Available from: https://www.statista.com/statistics/617136/digital-populationworldwide/.

6. Chris-Tin C, Lateef F. Consulting the Internet: using online search engines and its impact on the practice of medicine in the $21^{\text {st }}$ century. Edu Med $\mathrm{J}$. 2014;6(3):e40-50.

7. Muhamad M, Afshari M, Mohamed N. Internet use and breast cancer survivors.
Turkish Online J Educ Technol. 2011;10(4):241-7.

8. Chiu YW, Weng YH, Lo HL, Ting HW, Hsu CC, Shih YH. Physicians' characteristics in the usage of online database: a representative nationwide survey of regional hospitals in Taiwan. Inform Health Soc Care. 2009;34(3):127-35.

9. Peterson-Clark G, Aslani P, Williams KA. Pharmacists' online information literacy: An assessment of their use of Internet-based medicines information. Health Info Libr J. 2010;27(3):208-16.

10. Prendiville TW, Saunders J, Fitzsimons J. The information-seeking behaviour of paediatricians accessing web-based resources. Arch Dis Childh. 2009;94(8):6335.

11. Gilmour JA, Huntington A, Broadbent R, Strong A. Nurses' use of online health information in medical wards. J Adv Nurs. 2012;68(6):1349-58.

12. Beshir SA, Hanipah M. Knowledge, perception, practice and barriers of breast cancer health promotion activities among community pharmacists in two Districts of Selangor state, Malaysia. Asian Pac J Cancer Prev. 2012;13(9):4427-30.

13. Ong SW, Hassali MA, Saleem F. Community pharmacists' perspectives of online health-related information: A qualitative insight from Kuala Lumpur, Malaysia. Health Inf Manag J. 2018;47(3):132-9.

14. Bearman M, Bessell T, Gogler J, McPhee W. Educating Australian pharmacists about the use of online information in community pharmacy practice. Int J Pharm Pract. 2005;13(2):109-15.

15. Bennett NL, Casebeer LL, Kristofco R, Collins BC. Family physicians' information seeking behaviors: A survey comparison with other specialties. BMC Med Inform Decis Mak. 2005;5(1):9.

16. Peterson $\square$ Clark G, Aslani P, Williams KA. Pharmacists' online information literacy: An assessment of their use of Internet-based medicines information. Health Info Libr J. 2010;27(3):208-16.

17. McCaw B, McGlade K, McElnay J. The impact of the internet on the practice of general practitioners and community pharmacists in Northern Ireland. J Innov Health Inform. 2008;15(4):231-7.

18. Rasinski K. Designing reliable and valid questionnaires. The Sage Handbook of Public Opinion Research. 2008;361-74.

19. Bolarinwa OA. Principles and methods of validity and reliability testing of questionnaires used in social and health science researches. Niger Postgrad Med J. 2015;22(4):195.

20. Field A. Discovering statistics using IBM SPSS statistics. $4^{\text {th }}$ ed. London, UK: Sage; 2013.

21. Pallant J. SPSS survival manual: McGraw-Hill Education (UK). 2013.

22. Bennett NL, Casebeer LL, Kristofco RE, Strasser SM. Physicians' Internet information-seeking behaviors. J Contin Educ Health. 2004;24(1):31-8.

23. Lupiáñez-Villanueva F, Ángel MM, Torrent J. Opportunities and challenges of Web 2.0 within the health care systems: An empirical exploration. Inform Health Soc Care. 2009;34(3):117-26.

24. Pharmacy Council of Pakistan. Aims and Objectives of the Pharm.D. Program. 2013. [5 December 2020]. Available from: https://www.pharmacycouncil.org.pk/ doc/Pharm\%20D\%20Curriculum\%20Final\%202013.pdf.

25. Wong PJ, Ko Y, Sklar GE. Identification and evaluation of pharmacists' commonly used drug information sources. Ann Pharmacother. 2009;43(2):347-52.

26. Muhlen MV, Ohno-Machado L. Reviewing social media use by clinicians. J Am Med Inform Assoc. 2012;19(5):777-81.

27. Shcherbakova N, Shepherd M. Community pharmacists, Internet and social media: An empirical investigation. Res Social Adm Pharm. 2014;10(6):e75-85.

28. Al-Farsi SM, AIRahbi HAM, Chitme HR. Information resources available at community pharmacies in Oman. Int J Pharm Sci. 2014;5(6):2320-9.

29. Casebeer L, Bennett N, Kristofco R, Carillo A, Centor R. Physician internet medical information seeking and online continuing education use patterns. J Contin Educ Health. 2002;22(1):33-42.

30. Grossman S, Zerilli T. Health and medication information resources on the World Wide Web. J Pharm Prac. 2013;26(2):85-94.

31. Pillai RK, Mehendale S, Awasthi S, Varman GR. The significance of research in post-graduate education and ways to facilitate. Clin Epidemiol Glob Health. 2015;3(2):58-62. 